\title{
Configurações
}

Revista de sociologia

$9 \mid 2012$

Trabalho e género: vidas precárias, percursos e acção colectiva

\section{Helena Machado e Filipe Santos (organização de) Justiça, ambientes mediáticos e ordem social V. N. Famalicão}

\section{Fernando Bessa Ribeiro}

\section{(2) OpenEdition}

\section{Journals}

Edição electrónica

URL: http://journals.openedition.org/configuracoes/1218

DOI: $10.4000 /$ configuracoes. 1218

ISSN: 2182-7419

\section{Editora}

Centro de Investigação em Ciências Sociais

Edição impressa

Data de publição: 30 junho 2012

Paginação: 219-222

ISSN: 1646-5075

Refêrencia eletrónica

Fernando Bessa Ribeiro, « Helena Machado e Filipe Santos (organização de) Justiça, ambientes mediáticos e ordem social V. N. Famalicão ", Configurações [Online], 9 | 2012, posto online no dia 27 novembro 2013, consultado o 22 setembro 2020. URL : http://journals.openedition.org/ configuracoes/1218; DOI : https://doi.org/10.4000/configuracoes.1218

Este documento foi criado de forma automática no dia 22 setembro 2020.

(c) CICS 


\title{
Helena Machado e Filipe Santos (organização de) Justiça, ambientes mediáticos e ordem social $V . N$. Famalicão
}

\author{
Fernando Bessa Ribeiro
}

\section{REFERÊNCIA}

Helena Machado e Filipe Santos (organização de) Justiça, ambientes mediáticos e ordem social V. N. Famalicão, Húmus, 2010

1 Organizado por Helena Machado e Filipe Santos, este livro é um trabalho meritório e inovador sobre um campo social da maior importância nas sociedades contemporâneas: o da justiça. É de salientar que o livro exprime, e não é aspecto de menor importância, também a crescente internacionalização das ciências sociais em Portugal, neste caso da sociologia, através do envolvimento de investigadores em redes internacionais de investigação e produção de ciência.

2 Sublinhe-se que o livro de Helena Machado e Filipe Santos foi originalmente publicado em língua inglesa. Outro aspecto a destacar é a filiação disciplinar e interesses de investigação muito diversificados, combinando fundamentalmente a sociologia (Helena Machado, Filipe Santos e Chris Greer), com o direito e a criminolgia (Valerie Hans e Susanne Karstedt, entre outros).

o livro é constituído por seis textos - antecedidos por uma introdução a cargo dos organizadores - que analisam tópicos relacionados com a mediatização da justiça, suportados por enquadramentos teóricos pertinentes e, em alguns casos, muito sofisticados. Temos assim um enfoque que atravessa todo o livro: a mediatização da justiça, entendida por Machado e Santos como 
um dos mais prementes desafios para as sociedades actuais na medida em que é dada ao público a possibilidade de observar os procedimentos, regras e o funcionamento da justiça. Por via das imagens e discursos produzidos nos média, o público recebe dados que lhe permitem elaborar concepções e representações acerca do sistema de justiça e da ordem social vigente, plasmada ou mesmo ausente nos códigos e disposições legais (p. 7).

Apesar de ainda pouco estudado em Portugal, também no campo da justiça se joga a democracia e a cidadania. Como referem Machado e Santos, a abrir a introdução, "nas últimas décadas, o debate em torno das relações entre os tribunais e a comunicação social tem estado no epicentro da discussão pública sobre o estado da justiça (e da democracia) em vários países" (p. 7). As questões da justiça, crescentemente mediatizadas e, é claro, politizadas, não são um assunto menor nas sociedades contemporâneas. Analisando a acção dos média, este livro concorre para não deixar este campo nas mãos dos jornalistas e de outros produtores de opinião que, não raro, estão vinculados a interesses económicos e políticos, quase sempre nunca explicitados e que falam em nome daquilo que vagamente definem como opinião pública e o interesse geral. Daí que me parece que o interesse em relação à justiça faz parte do interesse político dos cidadãos pelas coisas e problemas do nosso mundo. Por outras palavras, a indiferença política em relação à justiça constitui mais uma das múltiplas formas de alheamento em relação ao mundo, uma maneira de o olhar como se fosse espectáculo, bem ao gosto de algumas abordagens pós-modernas. Dando seguimento a esta perspectiva, na justiça, à semelhança do que acontece no meio académico, não existe torre de marfim segura e sólida, imune ao mundo e seus interesses.

5 Para o cidadão será certamente relevante e útil saber que as relações entre a justiça (e a polícia), por um lado, e os média, por outro, são complexas, muitas vezes conflituosas e reflectem relações de força e interesses não raro antagónicos. Nesse sentido, o texto de Chris Greer e Eugene McLaughlin sobre os protestos populares contra a reunião do G20 em Londres, em Abril de 2009, procede a uma análise notável dos conflitos que se podem gerar em torno de um acontecimento e do papel da acção individual e colectiva através da utilização virtuosa das novas tecnologias para mudar a relação de forças em termos mediáticos, passando-se da "violência dos manifestantes" para a "violência policial". Tornando evidente que existe margem de manobra para a agência humana, os autores escrevem que "o cidadão-jornalista fornece uma fonte valiosa adicional de informação em tempo real que pode desafiar ou confirmar a versão institucional dos acontecimentos" (p. 129).

6 É pertinente notar que o interesse mediático pela justiça - a que corresponde uma preocupação crescente por informar/mediatizar/manipular a acção da justiça por parte dos operadores (veja-se, a propósito, os três últimos capítulos sobre justiça, informação e comunicação e a acção da polícia no Reino Unido) - ocorre num tempo marcado por um endurecimento penal. Ao mesmo tempo que o Estado vai emagrecendo a nível social e económico, assistimos ao seu engordar a nível securitário e punitivo; enquanto os governos vão cortando nas despesas sociais - na saúde, na segurança social, na educação - ora argumentando com o ajustamento estrutural, ora argumentando com a imperiosa racionalização mercantil, vão crescendo os orçamentos para os aparelhos policial, judicial e penitenciário. Por outras palavras, como escreve Loïc Wacquant, em As prisões da miséria (Oeiras, Celta Editora, 2000), "à atrofia deliberada do Estado social corresponde a hipertrofia do Estado penal: a miséria e o definhamento de um tem por contrapartida directa e necessária a grandeza e a prosperidade insolente do outro" (p. 
74). Conquanto Susanne Karstedt não faça essa ligação, não pude deixar de relacionar o seu texto sobre o uso das emoções na justiça criminal com o quadro sociopolítico em que vivemos. Ao valorizar as emoções das vítimas, as actuais tendências (quase) hegemónicas no direito não deixam de contribuir para a disseminação do vento punitivo de que nos fala Wacquant, com todos os riscos daí decorrentes. Como Karstedt justamente lembra, "o alimentar de emoções de repulsa tem levado as sociedades a tratar os grupos marginalizados como se fossem inferiores a seres humanos" (p. 32). Mais, como revela o caso de Scott Peterson assinalado pela autora (p. 34), as emoções (ou ausência delas) podem contribuir para a formação da culpabilidade ou da inocência.

7 De igual modo, as emoções estão presentes nos médias. 0 capítulo de Helena Machado e Filipe Santos sobre o conhecido e controverso caso do desaparecimento de Madeleine Mcann no Algarve mostra como as emoções foram "jogadas" pelos média, fazendo com que os pais passassem de anjos a vilões num punhado de meses, à medida que a investigação se ia desenrolando e com isso alimentando um fluxo noticioso que permitia sustentar audiências e ganhos económicos. Aqui é conveniente que, não podendo escapar às lógicas que organizam a acção do capitalismo, também o campo mediático se confronta com a crescente concentração das empresas produtoras de informação e conteúdos mediáticos, sob o comando de grandes grupos financeiros e industriais. Ou seja, da fusão do cultural com o económico, como assinala justamente Fredreric Jameson (A cultura do dinheiro, Petrópolis, Vozes, 2001) com tudo o que isso significa em termos de valores, prioridades e formas de fazer comunicação social.

8 Ao longo desta recensão referiu-se amiúde cidadania e democracia. Há que destacar que este livro é uma expressão concreta do compromisso de Helena Machado e Filipe Santos com os cidadãos e o debate democrático. Constituindo "uma acção de divulgação de conhecimento científico levada a cabo no âmbito do projecto de investigação Justiça, media e cidadania", como referem os organizadores (p.11), este livro procura fazer entrar no debate público os resultados da investigação e a reflexão teórica, neste caso sobre justiça e media. Trata-se de uma outra e mais virtuosa forma de prestação de contas aos financiadores por parte de Helena Machado e Filipe Santos, neste caso directamente aos cidadãos que, com os seus impostos, pagam as nossas investigações, através da publicação de um livro que interpela fundo as questões da justiça e sua mediatização.

9 Em suma, estamos perante um livro interpelador e surpreendente. Sendo capaz de responder aos objectivos formulados pelos organizadores -

contribuir para alargar o âmbito da análise crítica e reflexão sobre os encontros e desencontros entre a justiça e os média, tendo como objectivo familiarizar o público português com outras dimensões possíveis da discussão: desde a importância das emoções no direito e na administração da justiça criminal; aos impactos da cobertura mediática de casos criminais nas representações sobre justiça, ordem social e nos chamados 'julgamentos mediáticos'; passando por perspectivas mais dirigidas ao futuro da justiça e seus operadores em paisagens crescentemente mediatizadas e assentes no poder de difusão de novas tecnologias, que colocam desafios às relações entre os tribunais, a polícia e os médias, procurando interrogar, inclusivamente, o papel dos cidadãos neste cenário de mudança (p. 8)

- os cidadãos interessados nesta temática, sobretudo os comprometidos com o aprofundamento da transparência e do escrutínio da justiça, enfim, com o alargamento da cidadania e participação democráticas, terão acesso a elementos bastantes que 
contribuirão para formar uma opinião mais esclarecida, justificando assim plenamente o tempo dispendido com a sua leitura.

\section{AUTORES}

\section{FERNANDO BESSA RIBEIRO}

Escola de Ciências Humanas e Sociais Universidade de Trás-os-Montes e Alto Douro e Centro de Investigação em Ciências Sociais da Universidade do Minho, fbessa@utad.pt 